\title{
Bater não educa ninguém! Práticas educativas parentais coercitivas e suas repercussões no contexto escolar
}

Naiana Dapieve Patias

Aline Cardoso Siqueira

Ana Cristina Garcia Dias

Universidade Federal de Santa Maria

Contato:

Ana Cristina Garcia Dias

Universidade Federal de Santa Maria

Programa de Pós-Graduação em Psicologia

Santa Maria/RS

anacristinagarciadias@gmail.com

\section{Resumo}

0 objetivo deste artigo é refletir sobre os efeitos das práticas educativas coercitivas para o desenvolvimento da criança e do adolescente, buscando compreender sua influência no comportamento e na aprendizagem em ambiente escolar. A partir da análise assistemática de estudos sobre o tema, foi possível compreender que as estratégias coercitivas que se utilizam da força física para educar estão associadas a resultados negativos no desenvolvimento humano da criança e do adolescente, como comportamentos agressivos e baixa autoestima, constituindo-se em risco ao desenvolvimento saudável. Contudo, tais práticas são compartilhadas socialmente e consideradas naturais pelas famílias, não havendo, muitas vezes, o conhecimento de outras formas de educar. Sendo a escola um importante ambiente de interação das crianças, ela tem sido chamada a engajar-se nessa temática. Assim, discutem-se formas de instrumentalizar os profissionais da educação para a identificação dos casos de uso de estratégias coercitivas e violência física na educação dos filhos, como também ações preventivas junto aos estudantes e à comunidade. Para que o propósito seja alcançado, órgãos responsáveis pela defesa dos direitos da criança e psicólogo escolar poderão atuar juntamente com a escola, auxiliando-a nesse processo. 0 psicólogo pode trabalhar com os pais no sentido de apresentar formas de educar que não passem pela perspectiva da violência, prevenindo, assim, danos ao desenvolvimento e comportamentos que dificultam a aprendizagem. Fomentar reflexões sobre essa problemática fará com que os valores da educação sem violência tomem espaço nas famílias, contribuindo para que as crianças tornem-se adultos saudáveis no futuro.

\section{Palavras-chave}

Educação - Família - Escola - Prática coercitiva. 


\section{Hitting does not educate! Coercive parental education practices and their repercussions in the school context}

Naiana Dapieve Patias

Aline Cardoso Siqueira

Ana Cristina Garcia Dias

Universidade Federal de Santa Maria

Contact:

Ana Cristina Garcia Dias

Universidade Federal de Santa Maria

Programa de Pós-Graduação em Psicologia

Santa Maria/RS

anacristinagarciadias@gmail.com

\begin{abstract}
The objective of this article is to reflect upon the effects of coercive education practices on the development of the child and the adolescent, seeking to understand their influence on behavior and learning within the school context. Based on the unsystematic analysis of studies on the theme, it was possible to understand that the coercive strategies that made use of physical force to educate are associated to negative results for the human development of the child and the adolescent, such as aggressive behavior and low self-esteem, constituting thereby a risk to their healthy development. Nevertheless, these practices are socially shared and regarded as natural by families, with other forms of educating often being unknown. With the school being regarded as an important space for the interaction of children, it has been called upon to join in this issue. Thus, forms are discussed of giving instruments to the professionals of education to help them identify cases where coercive strategies and physical violence are being used in the education of children, as well as to help them with preventive actions with students and with the community. In order to allow this purpose to be fulfilled, the bodies responsible for the defense of the rights of children, as well as the school psychologist, can act alongside the school, helping it in this process. The psychologist can work with parents to introduce them to forms of education that avoid the perspective of violence, thereby preventing future developmental damage and behavior that will hinder learning. Fostering reflections about this problem will allow the values of non-violence education to flourish among families, contributing to turn children into future healthy adults.
\end{abstract}

\section{Keywords}

Education - Family - School - Coercive practice. 
Educar é uma preocupação constante de muitos pais, que se questionam se a forma como criam seus filhos e estabelecem limites está adequada. Essa preocupação é legítima, pois a família consiste no primeiro ambiente social de que a criança participa, em que ela aprende regras e modos de se relacionar com o outro; assim, as interações familiares fundamentam as relações da criança na sociedade. Segundo Martins (2009), a base necessária para a socialização da criança é de responsabilidade dos pais, os quais devem conferir ao filho um ambiente incentivador e seguro no qual ele possa desenvolver-se. A família possui a função de ser fonte de segurança, afeto, proteção e bem-estar, mas isso nem sempre ocorre (SHAFFER, 2005).

É na família que a criança assimila algumas regras que posteriormente irá utilizar em outros ambientes, tais como a escola. A socialização da criança pode ocorrer por meio de vivências propostas nas práticas educativas parentais. Estas são estratégias que os pais utilizam para atingir objetivos específicos no que diz respeito a vários aspectos do comportamento infantil. Tais estratégias podem incluir a utilização de explicações e punições, bem como o uso de recompensas (CECCONELLO; DE ANTONI; KOLLER, 2003; REPPOLD et al., 2002; SAMPAIO, 2007; TEIXEIRA; BARDAGI; GOMES, 2004).

Na literatura, as práticas educativas são mencionadas como sendo, muitas vezes, fatores de risco ou de proteção para o desenvolvimento da criança e do adolescente. Considera-se como fatores de risco as condições ou variáveis que estão associadas a uma alta probabilidade de ocorrência de resultados negativos ou indesejáveis no desenvolvimento da criança e do adolescente, resultados estes que podem comprometer sua saúde, seu bem-estar ou sua performance social (JESSOR et al., 1995). Por outro lado, os fatores de proteção são compreendidos como condições ou variáveis que diminuem os fatores de risco, isto é, modificam, melhoram ou alteram a resposta do indivíduo a ambientes hostis que predispõem as consequências mal adaptativas
(HUTZ, 2002; RUTTER, 1985, 1987, 1996). 0 objetivo deste estudo é refletir sobre os efeitos das práticas educativas coercitivas para o desenvolvimento da criança e do adolescente, buscando compreender sua influência no comportamento e na aprendizagem na escola. A reflexão se dará por meio de uma breve revisão assistemática da literatura, a partir de alguns livros e artigos nacionais e internacionais de autores expoentes na área sobre o tema. Tais autores partem de diferentes perspectivas teóricas, sendo que as principais delas são baseadas na psicologia do desenvolvimento, na aprendizagem social e na psicologia cognitivo-comportamental.

\section{Método}

Primeiramente, foi realizado um levantamento de artigos no portal da SciELO (Scientific Electronic Library Online) ${ }^{1}$ com os seguintes descritores: práticas educativas parentais; família and educação and violência. Foram encontrados apenas dez artigos com a expressão-chave práticas educativas parentais. Já com a combinação entre as palavras família, educação e violência, foram encontrados 22 artigos. Com o intuito de verificar quais artigos seriam selecionados para a análise, foram lidos os títulos e resumos dos 32 artigos encontrados na busca. Como critério de inclusão, determinou-se que os títulos ou os resumos deveriam tratar de práticas educativas parentais relacionadas a situações de violência.

A análise foi realizada conforme a metodologia proposta por Gil (2006). Para esse autor, a leitura dos trabalhos é composta por quatro etapas: leitura exploratória, seletiva, analítica e interpretativa. Assim, os 32 artigos foram submetidos a uma leitura seletiva que buscou delimitar a amostra de artigos a serem lidos em sua integra e que fariam parte do corpus de análise sistemática. Do total dos trabalhos, 23 foram excluídos por não tratarem diretamente do foco da pesquisa. Para a determinação desse corpus,

1- $<$ http://www.scielo.br>. 
tomou-se por base a questão principal do estudo: práticas educativas parentais e violência.

Todos os nove artigos selecionados foram lidos e, após isso, a partir das referências citadas em cada artigo, foram consultados novos artigos e livros, quando se percebeu que as referencias ou citações repetiam-se. Surgiram, então, três grandes categorias de análise. As duas primeiras foram: práticas educativas parentais e práticas educativas parentais de risco para o desenvolvimento da criança e do adolescente. Por fim, considerou-se importante incluir a terceira categoria - comportamentos aprendidos na família e sua influência no ambiente escolar -, visando discutir a implicação desse tema no contexto escolar.

\section{Práticas educativas parentais}

De acordo com Weber (2007), são três os fatores que influenciam o comportamento humano: a herança genética, as aprendizagens realizadas desde o nascimento e as influências culturais presentes em todas as sociedades. Há, ainda, uma interação entre os fatores hereditários e ambientais, sendo que alguns genes influenciam alguns comportamentos. No entanto, a genética não é determinante por si só, já que é influenciada pelo ambiente em que a pessoa encontra-se inserida. Assim, muitos dos comportamentos das crianças são frutos da interação com os pais e/ou cuidadores (WEBER, 2007).

Inicialmente, aspectos biológicos tendem a ser importantes fatores de influência; porém, mais tarde, a ação do ambiente possui maior força, e é aí que se inserem as práticas educativas parentais. De fato, o modo de criação adotado pela família para educar uma criança é fundamental para seu desenvolvimento e para a construção de sua identidade. Os pais e educadores influenciam em valores, comportamentos, habilidades e gostos, afetando, assim, a personalidade de cada criança (WEBER, 2007).

Para Cecconello, De Antoni e Koller (2003), os pais utilizam-se de estratégias educativas com a finalidade de atingir objetivos específicos no que diz respeito às habilidades acadêmicas, sociais e afetivas das crianças. Sendo assim, as práticas educativas referem-se à forma como os pais educam seus filhos em situações do dia a dia relacionadas a hábitos de higiene, alimentação e normas de interação social. Desse modo, os pais podem utilizar vários métodos para educar seus filhos, dependendo da situação em questão (ALVARENGA; PICCININI, 2007).

Hoffman (1960) é um dos autores que estudou as práticas educativas parentais, enfatizando a concentração de poder na figura dos pais. 0 autor considera que, os pais podem lançar mão de duas formas diferentes de poder para alterar o comportamento dos filhos. Uma das formas é a disciplina indutiva, que faz uso da explicação para modificar de forma voluntária o comportamento da criança. Os pais comunicam ao filho seu desejo de que ele modifique seu comportamento e, dessa forma, induzem-no a obedecer por meio do direcionamento de sua atenção para as consequências de seu comportamento (HOFFMAN, 1975).

A outra forma de modificar o comportamento dos filhos definida por Hoffman (1960, 1975) é a disciplina coercitiva, estratégia que utiliza-se da coerção. Nesse tipo de disciplina, os pais podem recorrer à ameaça ou ao uso direto de força, punição física e privação de privilégios. A disciplina coercitiva reforça o poder parental, utilizando a aplicação direta da força e do poder dos pais e provocando o controle do comportamento a partir de ameaça e sanções externas. Tal estratégia pode evoluir para situações de violência mais intensas. Segundo alguns autores, filhos que são educados a partir dessa concepção de educação podem apresentar diversos problemas psicológicos e comportamentais (CECCONELLO; DE ANTONI; KOLLER, 2003, REPPOLD et al., 2002).

De fato, ainda no que diz respeito às práticas educativas coercitivas, Patterson, DeBaryshe e Ramsey (1989) apontam para uma relação entre elas e comportamentos antissociais em crianças e adolescentes e, mais tarde, 
a delinquência. Assim, torna-se importante discutir as consequências da disciplina coercitiva para o desenvolvimento da criança e do adolescente e o modo como essa forma de disciplina influencia o ambiente escolar.

\section{Práticas educativas parentais de risco para o desenvolvimento da criança e do adolescente}

Para a compreensão dos riscos das práticas educativas parentais severas, deve-se levar em consideração que comportamentos aprendidos na primeira infância serão utilizados em novas situações com as quais a criança e o adolescente se depara, por exemplo, na escola (BANDURA, 1962; COSTA, 2008; MALDONAD0; WILLIAMS, 2005). A partir da revisão dos artigos pesquisados, percebe-se que muitos pesquisadores têm-se preocupado em investigar a relação entre as práticas educativas e os problemas desenvolvimentais em crianças e adolescentes. Alguns estudos encontraram uma associação entre certas práticas educativas parentais e a etiologia do comportamento exteriorizado (agressão verbal ou física, destruição de objetos, mentira, roubo, habilidades sociais inadequadas) (BOLSONO-SILVA; MARTURANO, 2007; PATTERSON; DeBARYSHE; RAMSEY, 1989; REPPOLD et al., 2002; REPPOLD; PACHECO; HUTZ, 2005; SALVO; SILVARES; TONI, 2005; SZELBRACIKOWSI; DESSEN, 2007; WEBER; VIEZZER; BRANDENBURG, 2004; WEBSTER-STRATTON, 1997). Do mesmo modo, outros autores mencionam uma relação entre certas práticas educativas e a presença de comportamentos internalizados (retração social, ansiedade, depressão, baixa autoestima) (CECCONELLO; DE ANTONI; KOLLER, 2003; GOMIDE et al., 2005; OLIVEIRA et al., 2002; PINHEIRO et al., 2006; WEBER; VIEZZER; BRANDENBURG, 2004; WEBER, 2007).

Dentre as práticas que comprometem o desenvolvimento saudável de crianças e adolescentes, Reppold, Pacheco e Hutz (2005) indicam que a violência doméstica e todos os tipos de coerção utilizados (punição corporal, xingamentos etc.), a pouca interação familiar e a negligência são fatores que contribuem para a manifestação de problemas psicológicos e de comportamento infantojuvenis, tais como a agressividade. Os processos de coerção estão associados aos comportamentos agressivos tanto em meninos quanto em meninas (SZELBRACIKOWSI; DESSEN, 2007). Nesse sentido, parece haver um efeito recíproco entre a prática parental coercitiva e o comportamento antissocial desenvolvido por crianças e adolescentes (PATTERSON; DeBARYSHE; RAMSEY, 1989; SZELBRACIKOWSI; DESSEN， 2007; WEBER; VIEZZER; BRANDENBURG, 2004). Cecconello, De Antoni e Koller (2003) também observam que a utilização de estratégias coercitivas, tais como a punição, pode acarretar inúmeros prejuízos ao desenvolvimento psicológico da criança e do adolescente. Os filhos tendem a repetir o comportamento coercitivo de seus pais, principalmente na resolução de conflitos com seus pares (COSTA, 2008). Considerando que as práticas educativas coercitivas estão associadas ao desenvolvimento de comportamentos antissociais e delinquência em crianças e adolescentes, Patterson, DeBaryshe e Ramsey (1989) afırmam que, em famílias de crianças consideradas antissociais, estão presentes aspectos como disciplina inconsistente, pouco afeto positivo e envolvimento com a criança, bem como pobre monitoramento e supervisão das atividades. Esse controle excessivo baseado, muitas vezes, na punição física, aliado ao pouco investimento afetivo e a uma supervisão restrita, contribui para condutas antissociais, dentre outros problemas comportamentais.

Ainda, autores revelam que o controle excessivo exercido pelos pais na relação com os filhos impede o desenvolvimento de habilidades importantes à adaptação de crianças e adolescentes, tais como a autoestima e a autonomia (SZELBRACIKOWSI; DESSEN, 2007; WEBER, 2007). Szelbracikowsi e Dessen (2007) afirmam que as práticas educativas parentais são decisivas na promoção de comportamentos socialmente 
adequados nas crianças. No entanto, pais que exercem a disciplina de forma inconsistente têm pouca interação positiva com seus filhos. Além disso, pais que não monitoram ou supervisionam os filhos estão estimulando a presença de comportamentos inadequados.

Pesquisas recentes (CECCONELLO; DE ANTONI; KOLLER, 2003; MONTANDON, 2005; SALVADOR; WEBER, 2005) sobre os efeitos das práticas coercitivas (punição física, por exemplo) no desenvolvimento de crianças demonstram que tais práticas podem provocar emoções intensas - como hostilidade, medo e ansiedade - que interferem na capacidade de adaptação do comportamento à situação (WEBER; VIEZZER; BRANDENBURG, 2004; WEBER, 2007).

A punição corporal tem um efeito imediato e eficaz para o agressor [...]. Quem recebe a punição corporal geralmente sente dor física e também seus subprodutos emocionais, tais como raiva, culpa, vergonha, medo e ansiedade, que podem demorar a cicatrizar [...]. As crianças deixam de emitir o comportamento punido, não por terem aprendido o correto, mas para escaparem dos tapas e surras. (WEBER; VIEZZER; BRANDENBURG, 2004, p. 235)

Weber, Viezzer e Brandenburg (2004) afırmam que a punição corporal pode gerar um efeito imediato, funcionando no momento em que é aplicada. No entanto, há prejuízos a longo prazo para o indivíduo que recebe a punição, bem como para os outros indivíduos com os quais ele convive, já que há um maior risco para o desenvolvimento de criminalidade, delinquência e violência contra outras pessoas. No estudo desenvolvido por esses autores, foram comparados dois grupos (um de crianças que sofriam abuso físico e outro de crianças que não sofriam esse tipo de abuso) no que se refere à utilização de práticas educativas. As crianças do primeiro grupo apresentaram menor autoestima, comportamento mais agressivo, altos níveis de sintomas psiquiátricos, bem como baixo bem-estar geral quando comparadas às crianças que não sofriam abuso físico.

As práticas coercitivas são aversivas, em geral, e provocam emoções negativas como medo e ansiedade, predispondo o indivíduo a fugir, retrucar e/ou agredir seu agressor/punidor. Elas têm como consequência a ansiedade infantil e juvenil, e muitas vezes utilizam-se da ameaça de rompimento do laço emocional entre os pais e a criança, sendo esta uma forma psicológica de punição que se expressa na forma de indiferença, isolamento da criança ou ameaça da perda de amor. Isso resulta em uma insegurança na criança em relação à disponibilidade e ao vínculo estabelecido pelos pais, bem como em um sentimento de desvalorização (REPPOLD; PACHECO; HUTZ, 2005; WEBER, 2007). Pode-se perceber que os efeitos negativos do uso da disciplina coercitiva pelos cuidadores vão além do surgimento de comportamentos desadaptativos, influenciando a percepção da criança e do adolescente sobre si mesmo.

De fato, autores como Bolsoni-Silva e Marturano (2002), Patterson, DeBayshe e Ramsey (1989), Dishion e Patterson (1992), Salvo, Silvares e Toni (2005) e Webster-Stratton (1997) revelam que, a longo prazo, a coerção influencia no surgimento de violência, depressão, ansiedade e comportamentos antissociais nos indivíduos. Dessa forma, no ambiente familiar, o uso da coerção como forma de educar está estritamente vinculado ao desenvolvimento de comportamentos agressivos e antissociais (WEBSTER-STRATTON, 1997), além da falta de habilidades sociais (PATTERSON; DeBARYSHE; RAMSEY, 1989).

Segundo Cecconello, De Antoni e Koller (2003), a estratégia coercitiva contribui para intensificar a percepção de valores e do padrão de ação moral como externos à criança. Com isso, a criança precisa de um agente externo que regule seu comportamento, já que essa técnica não facilita a internalização de normas sociais, o que ocorre na utilização da disciplina indutiva. Reppold et al. (2002) afirmam que pais que utilizam estratégias indutivas, se comparados 
com aqueles que utilizam técnicas coercitivas, influenciam mais efetivamente o comportamento de crianças e adolescentes. Percebe-se então que estratégias educativas coercitivas comprometem o desenvolvimento de crianças e adolescentes, estando associadas tanto à emissão de comportamentos agressivos quanto a dificuldades para internalizar regras e valores.

Tendo em vista todos esses prejuízos ao desenvolvimento das crianças, por que os pais continuam a utilizar estratégias coercitivas na educação de seus filhos? Jaeger e Strey (2011) demonstram que, ao longo dos séculos, as estratégias coercitivas têm sido utilizadas na educação de crianças. 0 padrão de criação infantil utilizado socialmente poderia ser considerado, na atualidade, inclusive como característico de maus tratos. Esse padrão foi-se modificando com o tempo, mas ainda se encontra enraizada na sociedade a cultura da violência, entendida como forma de educação dos filhos. Segundo as autoras, tal concepção está fortemente associada à noção de que as crianças são propriedades dos pais e das mães, de modo que estes acreditam que têm direito de vida e de morte sobre seus filhos. É possível observar, ainda hoje, muitos casos de crianças mal tratadas em público por seus responsáveis sem que haja responsabilização ou advertência. Modificar as concepções sociais que geram e tornam naturais certos comportamentos compartilhados por uma sociedade não é fácil, e isso não pode ser realizado em um curto período de tempo. Contudo, o estranhamento de algumas pessoas ao que é considerado estabelecido e dado como natural pode levar a modificações nessas concepções a ponto de transformá-las. Esse é um dos objetivos que motivou a criação do ECA, o Estatuto da Criança e do Adolescente (BRASIL, 1990), e do Projeto de Lei $n^{0} 7.672$ (BRASIL, 2010).

0 ECA (BRASIL, 1990) preconiza o estabelecimento de medidas de proteção nos casos em que há ameaça ou ocorre uma violação, de fato, aos direitos da criança e do adolescente.
Todas as formas de violência são consideradas violações ao direito da criança, e, assim, o disciplinamento coercitivo pode estar na origem de muitas violações realizadas às crianças e aos adolescentes. Já o Projeto de Lei $\mathrm{n}^{0} \mathbf{7 . 6 7 2}$ (BRASIL, 2010), que altera o ECA, determina claramente que as crianças e os adolescentes devem ser educados sem a utilização de castigo corporal ou de tratamento cruel e degradante. Ele define como castigo corporal a ação de natureza disciplinar ou punitiva, com uso da força física, que resulta em dor ou lesão à criança ou ao adolescente. 0 tratamento cruel ou degradante refere-se à conduta que humilha, ameaça gravemente ou ridiculariza a criança ou o adolescente.

Tal projeto, também conhecido como Lei da Palmada, tem gerado controvérsias entre as pessoas, provocando opiniões favoráveis e desfavoráveis. Para alcançar seu objetivo, o PL estabeleceu as seguintes ações: a promoção e a realização de campanhas educativas e a divulgação dessa lei e dos direitos humanos; a inclusão nos currículos escolares, em todos os níveis de ensino, de conteúdos relativos aos direitos humanos e à prevenção de todas as formas de violência contra a criança e o adolescente; a formação continuada dos profissionais que atuam na promoção dos direitos de crianças e adolescentes; o apoio e o incentivo às práticas de resolução pacífica de conflitos, dentre outras ações (BRASIL, 2010).

Considerando que os comportamentos aprendidos no ambiente familiar são, muitas vezes, repetidos por crianças e adolescentes em outros contextos (BANDURA, 1962; COSTA, 2008), como na escola, e que esta tem sido constantemente chamada a contribuir no campo da garantia dos direitos da criança e do adolescente, torna-se fundamental compreender como tal estratégia utilizada pelos pais na educação dos filhos influencia o comportamento manifesto na escola e a aprendizagem da criança e do adolescente. Além disso, é necessário discutir como a escola tem recebido e exercido essas novas funções. 
Comportamentos aprendidos na família e sua influência no ambiente escolar

A função primordial da escola, como sustenta Outeiral e Cerezer (2005), é educar, ou seja, colocar para fora o potencial do indivíduo e oferecer um ambiente propício para que esse processo se desenvolva. 0 termo educar difere de ensinar, que significa colocar signos para dentro do indivíduo. Quando a criança (ou o adolescente) chega à escola, traz seus aspectos constitucionais e suas vivências familiares, mas o ambiente escolar também influenciará e será uma peça fundamental em seu desenvolvimento. Nesse sentido, a escola é um espaço de transicionalidade: não é mais o conhecido e protegido espaço familiar, nem o temido e desejado mundo adulto. Em tal contexto, a criança e o adolescente poderão exercitar seus passos em direção à independência, à individualização e à separação de seu grupo original (OUTEIRAL; CEREZER, 2005).

A escola é um importante ambiente de desenvolvimento e de interação da criança e do adolescente. Em decorrência disso, ela tem sido convocada a agir em diversas situações, como nos casos de violência contra a criança e o adolescente. Muitas vezes, a violência praticada no contexto familiar é silenciada, sendo a escola praticamente o único lugar no qual é possivel a identificação dessa violação. Por isso, é importante que o contexto escolar (direção, professores) esteja atento às manifestações comportamentais e subjetivas dos alunos, já que estas podem revelar muitos dos comportamentos e valores aprendidos no contexto familiar, independentemente da classe social da qual provém o aluno (VAGOSTELLO et al., 2003).

No que tange à identificação de punição física severa, que ocorre a partir do uso da disciplina coercitiva, entre os aspectos que os professores devem estar atentos estão: baixo rendimento escolar ou queda de performance; ausências frequentes; falta de atenção e de concentração. Além disso, os docentes devem observar mudanças no comportamento, tais como: a presença de agressividade, passividade, apatia e/ou choro frequente. Todos esses sintomas podem surgir em decorrência de abuso físico que a criança e/ou o adolescente esteja vivendo em outros contextos (AZEVEDO; GUERRA, 1989; DI LEO, 2011).

Para Di Leo (2011), fatores familiares estão entre as causas da violência nas escolas, visto que as famílias estão tendo dificuldades para colocar limites nos filhos. Além disso, quando os pais são divorciados, por exemplo, há uma dificuldade maior para educar os filhos. Di Leo (2011) acredita que a ausência do pai ou o trabalho da mãe fora do lar podem dificultar a adoção de limites aos filhos. Em muitas famílias monoparentais (ausência de um dos pais), inúmeras tarefas passam a ser de responsabilidade de apenas um dos pais, causando sobrecarga e potencializando o uso de disciplina coercitiva em detrimento da indutiva (JAEGER; STREY, 2011).

Além disso, esses aspectos acabam por refletir no contexto escolar. A criança educada a partir de estratégias coercitivas tende a utilizá-las na resolução de problemas e na interação com seus colegas e professores (DOS SANTOS; FERRIANI, 2007; MALDONAD0; WILLIAMS, 2005; RIOS; WILLIAMS, 2008; SIQUEIRA; ALVES; LEÃO, 2012). De fato, muitas crianças utilizam-se de força física quando contrariadas no contexto escolar. Esse episódio pode ocorrer devido à aprendizagem de que os conflitos se resolvem à força. Muitas vezes, é assim que tais crianças e adolescentes conseguem o que desejam em casa, agredindo os irmãos e até mesmo os pais (WEBER; VIEZZER; BRANDENBURG, 2004).

Miller (2008) também observa que, na escola, crianças pequenas, filhas de pais que utilizaram a coerção, na maioria das vezes são agressivas e hostis com outras crianças, sendo que também podem apresentar um comportamento retraído e medroso. Suas habilidades sociais tendem a ser inadequadas, pois não tiveram um modelo de resolução de problemas e de empatia adequado oferecido por seus cuidadores. Ainda, crianças e adolescentes agressivos na escola tendem a ser 
rejeitados pelos pares e estão mais vulneráveis a se envolver com grupos desviantes, assim como a apresentar vários tipos de transtorno de desenvolvimento, como o transtorno desafiador de oposição e o transtorno de conduta, dentre outros (AMERICAN PSYCHIATRIC ASSOCIATION, 2002; MALDONADO; WILLIAMS, 2005).

Outro aspecto consiste no uso de coerção nas relações entre os educadores e os estudantes. Ruotti (2010) destaca a existência de manifestações de violência na escola decorrentes das violências da realidade externa (da comunidade e do contexto familiar, por exemplo). Essas manifestações interferem na conduta dos educadores, dificultando o processo educacional. A fim de lidar com situações de violência, a escola acaba por repetir a violência externa por meio da coerção, agindo de forma punitiva.

É essa realidade externa que parece adentrar os muros escolares de duas formas distintas. De um lado, trazendo incertezas e riscos para os membros escolares e impedindo a ação educativa na forma principalmente da ação do tráfico de drogas. De outro, agindo, sobretudo, nas representações e práticas dos profissionais da escola. Isso porque a ameaça que constitui esse externo, na forma de violência, permeia fortemente as concepções dos profissionais sobre sua clientela e sobre os fins da educação e os meios necessários para realizá-los. (RUOTTI, 2010, p. 345)

Dos Santos e Ferriani (2007) afirmam que os comportamentos agressivos tanto de crianças como de adolescentes vividos na escola são um complicador para o trabalho dos professores, o que se deve, principalmente, à sobrecarga de trabalho que os professores possuem. Além disso, considera-se que, para que o professor consiga ensinar adequadamente, o ideal é que o ambiente de aprendizagem seja tranquilo e possibilite segurança e confiança. Quando há alunos agressivos, tal ambiente fica em desequilíbrio e o professor, além de ministrar os conteúdos, tem de contornar situações constrangedoras e perigosas, ensinando novos modelos de interação (SILVA, 2010; WEBER, 2007). Exemplos disso são as situações de bullying que ocorrem no contexto escolar, cujo agressor, geralmente, possui um histórico de violência intrafamiliar (SILVA, 2010).

Patterson, DeBaryshe e Ramsey (1989) afırmam que, na escola, as crianças que são educadas por meio de práticas educativas coercitivas tendem a possuir poucas habilidades sociais e a envolverem-se com grupos desviantes, além de serem mais rejeitadas pelos pares. Elas também possuem maiores dificuldades de aprendizagem, o que pode, comumente, levar ao fracasso escolar. Para Sapienza, AznarFarias e Silvares (2009), o oposto também pode ocorrer, ou seja, quando os pais utilizam estratégias educativas positivas, os filhos tendem a apresentar melhores resultados na escola, influenciados pelas competências sociais e pelo modo como são educados pelos pais.

Considerando que estratégias coercitivas podem evoluir para situações cada vez mais graves e sistemáticas de violência, é importante que os professores estejam atentos aos sinais de violência intrafamiliar. Azevedo e Guerra (1989) observam que alguns sinais são mais facilmente identificados (marcas corporais) do que outros (medo, tristeza). Essas características são encontradas em alunos que parecem sofrer algum tipo de violência na família. Além disso, professores podem identificar dificuldades de aprendizagem, baixo rendimento escolar, indisciplina, falta de concentração e motivação em sala de aula, aspectos estes que estão associados à violência intrafamiliar (GRANVILLE-GARCIA et al., 2009; SIQUEIRA; ALVES; LEÃO, 2012; VAGOSTELLO et al., 2003).

Muitas vezes, os professores conseguem perceber sinais de violência que são mais visíveis no comportamento e na aprendizagem de crianças e adolescentes, como demonstram os estudos de Granville-Garcia et al. (2009) e de Vagostello et al. (2003). Assim, percebe-se que a escola é chamada a manejar a agressividade 
e as situações de violência e de intimidação de alunos, o que lhe confere um papel importante no desenvolvimento, pois, nesse contexto, as crianças e os adolescentes podem ter contato com modelos de comportamento mais adaptativos.

De fato, a escola possui uma função relevante na identificação da violência cometida pela família (GRANVILLE-GARCIA et al., 2009). Os educadores são pessoas importantes e exercem influência sobre as crianças e os adolescentes. Além dos familiares, eles são as pessoas que têm maior contato, por longas horas, com as crianças e os adolescentes. Muitas vezes, eles são as pessoas adultas próximas em que os alunos confiam. Perante a suspeita de ameaça ou violação dos direitos da criança e do adolescente, é dever da escola realizar a notificação junto aos órgãos responsáveis e buscar a proteção do estudante em situação de risco (GRANVILLE-GARCIA et al., 2009; VAGOSTELLO et al., 2003). Sendo a escola, frequentemente, o único recurso que o aluno tem para romper o pacto do silêncio que acontece no contexto familiar, ela deve estar capacitada para fazer a identificação e a notificação dessas situações. Os agentes que nela atuam precisam estar habilitados para lidar com essas situações, devendo estar atentos para o diagnóstico precoce das situações de violência e de risco ao desenvolvimento (GRANVILLE-GARCIA et al., 2009; VAGOSTELLO et al., 2003). Contudo, não é sempre que os professores assumem tal tarefa e/ou demonstram engajamento nessa problemática (VIODRES INOUE; RISTUM, 2008).

Segundo Assis (1991), nem sempre há notificação, devido ao medo que o profissional tem de se envolver em conflitos particulares e de sofrer ou gerar represálias direcionadas tanto a si como à vítima por parte dos agressores. Outro estudo demonstra que somente um pequeno número de profissionais de educação realiza notificação a órgãos competentes nos casos de suspeita de abuso sexual (BRINO; WILLIAMS, 2003). Segundo as autoras desse trabalho, tal atitude pode ser decorrente do não conhecimento do ECA (BRASIL, 1990), da presença de crenças inadequadas sobre o papel do professor e do medo da ocorrência de represálias dos pais ou responsáveis pelos alunos.

Por sua vez, a pesquisa de Viodres Inoue e Ristum (2008), que buscou identificar situações de violação dos direitos denunciadas por educadores em 2.522 casos de violência sexual atendidos em uma instituição voltadas a vítimas de violência, identificou que apenas 22 notificações foram realizadas por educadores. Os pesquisadores acreditam que esse número reduzido de notificações possa ser explicado pelo fato de os educadores não conhecerem os direitos das crianças e dos adolescentes, nem sua responsabilidade na garantia desses direitos (VIODRES INOUE; RISTUM, 2008).

A tarefa de proteção à criança e ao adolescente tem sido sentida como mais uma atribuição do educador, que em muitos casos já lida com inúmeros fatores estressores presentes em seu cotidiano, como baixos salários, pouca valorização profissional, desmotivação dos alunos etc. (MASSABNI, 2011). Estar atento aos sinais de estratégias coercitivas passiveis de se tornarem maus tratos físicos pode acentuar ainda mais os níveis de estresse vivenciados por muitos profıssionais da educação brasileira.

\section{Considerações finais}

Neste artigo, enfocaram-se os aspectos familiares - mais especificadamente, as práticas educativas parentais coercitivas - como um dos fatores que influenciam de maneira negativa no desenvolvimento de crianças e adolescentes, sendo observados efeitos decorrentes no contexto escolar. Contudo, é importante lembrar que o fenômeno da violência, seja na sociedade, na família ou na escola, é multideterminado, não podendo ser reduzido a explicações simplistas ou unicausais que desconsideram as interações entre diferentes fatores. Assim, destaca-se que, apesar de este estudo ter buscado realizar uma análise detalhada das relações entre práticas educativas 
familiares, violência e contexto escolar, ele limitou-se a um recorte possível de análise sobre um fenômeno complexo e multideterminado em que diferentes fatores se encontram envolvidos.

No que se refere ao objeto de análise em questão, a literatura evidencia os efeitos negativos do uso de estratégias disciplinares coercitivas no desenvolvimento dos filhos, como também seu reflexo na escola. A análise dos estudos permite compreender tais estratégias como fatores de risco ao desenvolvimento das crianças e dos adolescentes. Em algumas culturas, o uso de punição corporal na educação dos filhos é aceito e alicerçado na crença de que a força e os valores autoritários dos pais sobre os filhos garantem uma boa educação. Isso, porém, é um equívoco, uma vez que essas práticas geram medo, insegurança e baixa autoestima. Ademais, muitos pais e mães usam estratégias coercitivas na educação de seus filhos e julgam-nas eficientes por não conhecerem outra forma de educá-los ou por terem sido eles próprios educados sob a égide dessas práticas. Assim, percebe-se um desconhecimento das pessoas sobre outras formas de educar e sobre os efeitos de uma educação baseada na punição corporal. A punição (prática coercitiva) acarreta consequências psicológicas negativas no desenvolvimento infantil, não sendo uma estratégia eficaz de educar os filhos.

As crianças e os adolescentes tendem a seguir os modelos de educação de seus pais e, dessa forma, tendem a reproduzir a violência na relação com os outros na família e em demais contextos, como a escola. Isso dificulta a aprendizagem e o desenvolvimento de relacionamentos saudáveis com colegas e professores. Torna-se necessário promover uma conscientização quanto aos prejuízos do uso das estratégias coercitivas junto aos pais, para que os mesmos compreendam os riscos que estão envolvidos. Desse modo, os pais possuirão habilidades sociais educativas específicas, dentre elas, a habilidade de expres- sar sentimentos e opiniões, bem como saberão estabelecer limites, evitando a coerção e impedindo dificuldades escolares e de socialização infantil. Além disso, é importante discutir e construir em conjunto com esses pais, seja na escola ou em fóruns de discussão mais amplos, como a mídia, diferentes estratégias de educação, instrumentalizando-os no uso de práticas educativas indutivas. Nesse sentido, segundo Weber, Viezzer e Brandenburg (2004), os pais devem obter o conhecimento de outras formas de educar mais eficazes, a fim de criar e manter repertórios comportamentais adequados, colaborando para o desenvolvimento de habilidades sociais da criança. Ao considerar que as práticas educativas coercitivas estão fortemente enraizadas na sociedade, espera-se que as mudanças em relação a elas sejam lentas e graduais.

Como forma de focalizar essa prática, criou-se o projeto de lei conhecido como Lei da Palmada, que tem promovido discussões sobre o desenvolvimento de práticas coercitivas na educação dos filhos. Embora se saiba que uma prática não é modificada por decreto, tal projeto de lei coloca o tema em foco e destaca os prejuízos da implementação de práticas coercitivas para o desenvolvimento de crianças e adolescentes. Assim, ele representa uma contribuição para a defesa e a garantia dos direitos dos indivíduos dessa faixa etária.

Uma vez que as práticas físicas punitivas podem evoluir para a ocorrência de violência física mais severa, é fundamental que sejam oferecidos subsídios às famílias que utilizam tais estratégias, auxiliando-as a fazerem uso de práticas mais eficazes na educação de seus filhos. A escola possui grande potencial para a identificação de tais práticas, podendo realizar encaminhamentos e também ações preventivas junto às famílias mais vulneráveis à utilização de práticas coercitivas. 0 psicólogo inserido no contexto escolar pode ajudar a escola a desenvolver essa tarefa, seja propondo palestras aos pais, seja 
realizando o acompanhamento das famílias com história de violência doméstica. Além disso, o psicólogo no contexto escolar pode desenvolver trabalhos de intervenção junto aos pais e professores por meio do treinamento de habilidades sociais e de resolução de problemas, por exemplo, a fim de desenvolver novas formas de manejar os comportamentos inadequados de crianças e adolescentes tanto em casa como na escola.

Apesar das fragilidades encontradas no contexto escolar, como falta de valorização profissional, baixa remuneração, altos níveis de estresse, violência comunitária, dentre outros fatores estressores, considera-se que a escola pode engajar-se no enfrentamento desse problema. Ela pode oferecer aos pais experiências e modelos de práticas educativas mais saudáveis e adequadas ao desenvolvimento de crianças e adolescentes. A realização de capacitação continuada sobre o tema poderia instrumentalizar os educadores nessa importante e difícil tarefa de prevenir e identificar as práticas educativas coercitivas. Tais experiências e modelos oferecidos pelos educadores podem levar ao desenvolvimento de valores e habilidades sociais que não haviam sido desenvolvidas no ambiente familiar, mas que são imprescindíveis para a convivência em sociedade. Oficinas de capacitação poderiam ser realizadas com a parceria de profissionais e estudantes das universidades, assim como profissionais da saúde, de Conselhos Tutelares, do CRAS e do CREAS podem atuar na capacitação dos professores a partir do oferecimento de minicursos a professores, pais e comunidade escolar, auxiliando a identificar as formas de violência em crianças e adolescentes. Esses profissionais e órgãos estão envolvidos no planejamento de políticas públicas de prevenção, identificação e intervenção, podendo auxiliar as escolas. As parcerias devem acontecer como forma de prevenção, antes mesmo que a violência seja identificada na escola. Se na escola há um psicólogo, este pode, juntamente com outros profissionais da rede, pensar estratégias para prevenir a violência tanto no ambiente escolar, como na família. Quando a violência é identificada, os profissionais podem então auxiliar a minimizá-la a partir, por exemplo, de cursos para pais e professores sobre estratégias mais eficazes de educar.

Por outro lado, também há a possibilidade de que a escola seja um ambiente no qual existem práticas coercitivas (RUOTTI, 2010). Por exemplo, pode haver entre alunos ou entre professores e alunos formas hostis de relacionamento (agressão verbal e até mesmo agressão física). Esses aspectos devem ser trabalhados pelos profissionais, mostrando a importância de a escola servir como proteção para o desenvolvimento de crianças e adolescentes. Assim, é importante que os professores também sejam auxiliados por profissionais a administrarem situações de conflitos entre alunos e entre alunos e eles próprios. Um psicólogo escolar ou psicólogo da rede pode utilizar estratégias de mediação de conflitos, minimizando-os.

A instituição escolar, diante dos desafios atuais, não pode se eximir de agir na promoção de relações mais respeitosas. Culpar somente os alunos pelas várias manifestações de violência no ambiente escolar não soluciona o problema. (RUOTTI, 2010, p. 354)

Como visto, bater não educa ninguém! Pelo contrário, violência gera violência e adultos que receberam educação severa e/ou foram vítimas de maus tratos na infância tendem a repetir essa experiência com seus próprios filhos. Assim, pessoas tratadas com severidade quando jovens crescem utilizando práticas similares, pois a falta de modelos positivos leva à aceitação da punição de seus pais como algo normal (CECCONELLO; DE ANTONI; KOLLER, 2003; WEBER; VIEZZER; BRANDENBURG, 2004). Portanto, deve-se ter ciência de que disciplinar significa estabelecer limites, ensinar comportamentos adequados e corrigir 
os inadequados, bem como ajudar a criança a desenvolver autocontrole, encorajando-a a aprimorar sua autoestima e sua autonomia. A psicologia possui importante papel no sentido de trabalhar com famílias que utilizam erroneamente estratégias educativas coercitivas na educação de seus filhos, e também com famílias mais vulneráveis à utilização de tais estratégias (pais que foram educados com violência, por exemplo). Somente a conscientização dos prejuízos que a disciplina coercitiva acarreta poderá levar ao desenvolvimento de práticas educativas mais saudáveis e adaptativas. É tempo de transformar a maneira de educar os filhos, ensinando os valores da não violência e possibilitando que as crianças tornem-se adultos saudáveis que não reproduzirão a punição física com seus próprios filhos. 


\section{Referências}

ALVARENGA, Patrícia; PICCININI, Cesar. 0 impacto do temperamento infantil, da responsividade e das práticas educativas maternas nos problemas de externalização e na competência social da criança. Psicologia: Reflexão e Crítica, Porto Alegre, v. 20, n. 2, p. 314-323, 2007.

AMERICAN PSYCHIATRIC ASSOCIATION. Manual diagnóstico e estatístico de transtornos mentais (DSM-IV-TR). Tradução Cláudia Dornelles. 4. ed. rev. Porto Alegre: Artmed, 2002.

ASSIS, Simone Gonçalves de. Quando crescer é um desafio social: estudo sócio-epidemiológico sobre violência em escolares de Duque de Caxias. Dissertação (Mestrado) - Escola Nacional de Saúde Pública da Fundação Oswaldo Cruz, Rio de Janeiro, 1991.

AZEVEDO, Maria Amelia; GUERRA, Viviane Nogueira A. (Orgs.). Crianças vitimizadas: a síndrome do pequeno poder. São Paulo: Iglu, 1989.

BANDURA, Albert. Social learning through imitation. In: JONES, Marshall R. (Ed.). Nebraska symposium on motivation. Lincoln: University of Nebraska, 1962. v. 10, p. 211-274.

BOLSONI-SILVA, Alessandra Turini; MARTURANO, Edna. Práticas educativas e problemas de comportamento: uma análise à luz das habilidades sociais. Estudos de Psicologia, Natal, v. 7, n. 2, p. 227-235, 2002.

. A qualidade da interação positiva e da consistência parental na sua relação com problemas de comportamentos de préescolares. Interamerican Journal of Psychology, v. 41, n. 3, p. 349-358, 2007.

BRASIL. Lei no 8.069, de 13 de julho de 1990. Instituiu o Estatuto da Criança e do Adolescente e dá outras providências. Diário Oficial da União, Brasília, 1990.

Projeto de Lei $n^{0}$ 7.672, de 16 de julho de 2010. Altera a Lei no 8.069, de 13 de julho de 1990, que dispõe sobre 0

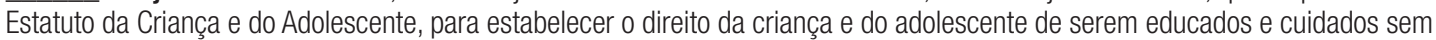
o uso de castigos corporais ou de tratamento cruel ou degradante. Brasília, 2010.

BRINO, Rachel de Faria; WILLIAMS, Lúcia C. de Albuquerque. Concepções da professora acerca do abuso sexual infantil. Cadernos de Pesquisa, São Paulo, n. 119, p. 113-128, 2003.

CECCONELLO, Alessandra Marques; DE ANTONI, Clarissa; KOLLER, Sílvia Helena. Práticas educativas, estilos parentais e abuso físico no contexto familiar. Psicologia em Estudo, Maringá. v. 8, n. especial, p. 45-54, 2003.

COSTA, Anna E. Bellico da. Modelação. In: BANDURA, Albert; AZZI, Roberta Gurgel; POLYDORO, Soely (Orgs.). Teoria social cognitiva: conceitos básicos. Porto Alegre: Artmed, 2008. p. 123-148.

DI LEO, Pablo Francisco. Violências y climas sociales en escuelas medias: experiencias de docentes y directivos. Educação e Pesquisa, São Paulo, v. 37, n. 3, p. 599-612, 2011.

DISHION, Thomas J.; PATTERSON, Gerald R. Age effects in parent training outcome. Behavior Therapy, v. 23, p. 719-729, 1992.

DOS SANTOS, Lana E. da Silva; FERRIANI, Maria das Graças C. A violência familiar no mundo da criança de creche e pré-escola. Revista Brasileira de Enfermagem, Brasília, v. 60, n. 5, p. 524-529, 2007.

GIL, Antonio Carlos. Métodos e técnicas de pesquisa social. 5. ed., 7. reimp. São Paulo: Atlas, 2006.

GOMIDE, Paula I. Cunha et al. Correlação entre práticas educativas, depressão, estresse e habilidades sociais. Psico-USF, Itatiba, v. 10, n. 2, p. 169-178, 2005.

GRANVILLE-GARCIA, Ana Flávia et al. Conhecimentos e percepção de professores sobre maus-tratos em crianças e adolescentes. Saúde Sociedade, São Paulo, v. 18, n. 1, p. 131-140, 2009.

HOFFMAN, Martin. Power assertion by the parent and its impact on the child. Child Development, v. 31, p. 129-143, 1960. 
HOFFMAN, Martin. Moral, internalization, parental power, and the nature of parent-child interaction. Developmental Psychology, v. 11, n. 2, p. 228-239, 1975.

HUTZ, Cláudio (Org.). Situações de risco e vulnerabilidade na infância e adolescência: aspectos teóricos e estratégias de intervenção. São Paulo: Casa do Psicólogo, 2002.

JAEGER, Fernanda Pires; STREY, Marlene Neves. Maternidade e violência em situações de opressão. In: JAEGER, Fernanda Pires; KRUEL, Cristina Saling; SIQUEIRA, Aline Cardoso (Orgs.). Parentalidade e contemporaneidade: os desafios para a psicologia. Santa Maria: Editora UNIFRA, 2011. p. 11-31.

JESSOR, Richard et al. Protective factors in adolescent problem behavior: moderator effects and developmental change. Developmental Psychology, v. 31, p. 923-933, 1995.

MALDONADO, Daniela P. Ado; WILLIAMS, Lúcia C. de Albuquerque. 0 comportamento agressivo de crianças do sexo masculino na escola e sua relação com a violência doméstica. Psicologia em Estudo, Maringá, v. 10, n. 3, p. 353-362, 2005.

MARTINS, Gabriela Dal Forno. Influência do apoio social sobre crenças e práticas maternas em capitais e pequenas cidades brasileiras. Dissertação (Mestrado) - Programa de Pós-Graduação em Psicologia, Universidade Federal de Santa Catarina, Florianópolis, 2009.

MASSABNI, Vânia G. Os conflitos de licenciandos e o desenvolvimento profissional docente. Educação e Pesquisa, São Paulo, v. 37 , n. 4, p. 793-808, 2011.

MILLER, Karen. Educação infantil: como lidar com situações difíceis. Porto Alegre: ArtMed, 2008.

MONTANDON, Cléopâtre. As práticas educativas parentais e a experiência das crianças. Educação e Sociedade, Campinas, v. 26 , n. 91, p. 485-507, 2005.

OLIVEIRA, Ebenézer et al. Estilos parentais autoritário e democrático-recíproco intergeracionais, conflito conjugal e comportamentos de externalização e internalização. Psicologia: Reflexão e Crítica, Porto Alegre, v. 15, n. 1, p. 1-11, 2002.

OUTEIRAL José; CEREZER, Cleon. 0 mal estar na escola. Rio de Janeiro: Revinter, 2005.

PATTERSON, Gerald R.; DeBARYSHE, Barbara D.; RAMSEY, Elizabeth. A developmental perspective on antisocial behavior. American Psychologis, v. 44, n. 2, p. 329-335, 1989.

PINHEIRO, Maria I. Santos et al. Treinamento de habilidades sociais educativas para pais de crianças com problemas de comportamento. Psicologia: Reflexão e Crítica, Porto Alegre, v. 19, n. 3, p. 407-414, 2006.

REPPOLD, Caroline T.; PACHECO, Janaína; HUTZ, Cláudio. Comportamento agressivo e práticas disciplinares parentais. In: HUTZ Cláudio (Org.). Violência e risco na infância e adolescência: pesquisa e intervenção. São Paulo: Casa do Psicólogo, 2005. p. 9-42.

REPPOLD, Caroline T. et al. Prevenção de problemas de comportamento e o desenvolvimento de competências psicossociais em crianças e adolescentes: uma análise das práticas educativas e dos estilos parentais. In: HUTZ, Cláudio (Org.). Situações de risco e vulnerabilidade na infância e adolescência: aspectos teóricos e estratégias de intervenção. São Paulo: Casa do Psicólogo, 2002. p. 9-51.

RIOS, Karine S. Augusto; WILLIAMS, Lúcia C. de Albuquerque. Intervenção com famílias como estratégia de prevenção de problemas de comportamento em crianças: uma revisão. Psicolologia em Estudo, Maringá, v. 13, n. 4, p. 799-806, out./dez. 2008.

RUOTTI, Caren. Violência em meio escolar: fatos e representações na produção da realidade. Educação e Pesquisa, São Paulo, v. 36, n. 1, p. 339-355. 2010

RUTTER, Michael. Resilience in the face of adversity: protective factors and resistance to psychiatric disorder. British Journal of Psychiatry, v. 147, p. 598-611, 1985.

Psychosocial resilience and protective mechanisms. American Journal Orthopsychiatry, v. 57, p. 316-331, 1987.

Psychosocial resilience and protective mechanisms. In: ROLF, Jon et al (Eds.). Risk and protective factors in the development of psychopathology. New York: Cambridge University Press, 1996. p. 181-214. 
SALVADOR, Ana P. Viezzer; WEBER, Lidia N. Dobrianskyj. Práticas educativas parentais: um estudo comparativo da interação familiar de dois adolescentes distintos. Interação em Psicologia, Curitiba, v. 9, n. 2, p 341-353, 2005.

SALVO, Caroline Guisantes de; SILVARES, Edwiges F. de Matos; TONI, Plínio Marco de. Práticas educativas como forma de predição de problemas de comportamento e competência social. Estudos de Psicologia, Campinas, v. 22, n. 2, p. 187-195, 2005.

SAMPAI0, Isabela T. A.. Práticas educativas parentais, gênero e ordem de nascimento dos filhos: atualização. Revista Brasileira Crescimento e Desenvolvimento Humano, São Paulo, v. 17, n. 2, p. 44-152, 2007.

SAPIENZA, Gabriela; AZNAR-FARIAS, Maria; SILVARES, Edwiges F. de Matos. Competência social e práticas educativas parentais em adolescentes com alto e baixo rendimento acadêmico. Psicologia: Reflexão e Crítica, Porto Alegre, v. 22, n. 2, p. 208-213, 2009.

SHAFFER, David R. Psicologia do desenvolvimento: infância e adolescência. Tradução da $6^{a}$ edição norte-americana Cíntia Regina Pemberton Cancissu. São Paulo: Pioneira, 2005.

SILVA, Ana B. Barbosa. Bullying: mentes perigosas nas escolas. Rio de Janeiro: Objetiva, 2010.

SIQUEIRA, Aline Cardoso; ALVES, Cássia Ferrazza; LEÃO, Flavia Elso. Enfrentando a violência: a percepção dos profissionais da educação sobre a violação dos direitos de crianças e adolescentes. Educação (UFSM), Santa Maria, v. 37, n. 2, p. 365-380, 2012.

SZELBRACIKOWSI, Adriane Corrêa; DESSEN, Maria Auxiliadora. Problemas de comportamento exteriorizado e as relações familiares: revisão de literatura. Psicologia em Estudo, Maringá, v. 12, n. 1, p. 33-40, 2007.

TEIXEIRA, Marco A. Pereira; BARDAGI, Marúcia Patta; GOMES, William Barbosa. Refinamento de um instrumento para avaliar responsividade e exigência parental percebidas na adolescência. Avaliação Psicológica, Porto Alegre, v. 3, n. 1, p. 1-12, 2004.

VAGOSTELLO, Lucilena et al. Violência doméstica e escola: um estudo em escolas públicas de São Paulo. Paidéia, Ribeirão Preto, v. 13, n. 26, p. 191-196, 2003.

VIODRES INOUE, Silvia Regina; RISTUM, Marilena. Violência sexual: caracterização e análise de casos revelados na escola. Estudos de Psicologia, Campinas, v. 25, n. 1, p. 11-21, 2008.

WEBER, Lidia N. Dobrianskyj. Eduque com carinho: equilíbrio entre amor e limites. 2. ed. rev. atual. Curitiba: Juruá, 2007. WEBER, Lidia N. Dobrianskyj; VIEZZER, Ana Paula; BRANDENBURG, Olivia Justen. 0 uso de palmadas e surras como prática educativa. Estudos de Psicologia, Natal, v. 9, n. 2, p. 227-237, 2004.

WEBSTER-STRATTON, Carolyn. Early intervention for families of preschool children with conduct problems. In: Guralnick, Michael J. (Org.). The effectiveness of early intervention. Baltimore: Paul H. Brookes, 1997. p. 429-453.

Recebido em: 02.02.2012

Aprovado em: 06.08.2012

Naiana Dapieve Patias é especialista em Criança e Adolescente em Situação de Risco pelo Centro Universitário Franciscano (UNIFRA) e mestre em Psicologia pela Universidade Federal de Santa Maria (UFSM). E-mail: naipatias@hotmail.com.

Aline Cardoso Siqueira é doutora em Psicologia pela Universidade Federal do Rio Grande do Sul (UFRGS) e docente do Departamento de Psicologia da Universidade Federal de Santa Maria (UFSM). E-mail: alinecsiq@gmail.com.

Ana Cristina Garcia Dias é doutora em Psicologia pela Universidade de São Paulo (USP) e docente da Pós-Graduação em Psicologia da Universidade Federal de Santa Maria (UFSM). 